\title{
A Sociedade da Informação na Economia Globalizada: Alguns Aspectos do Direito Cibernético
}

\author{
The Information Society and Global Economy: \\ Some Aspects of the Cybernet Law
}

\author{
Valkíria Aparecida Lopes Ferraro; Rogério Martins de Paula²; Renata Silveira de \\ Paiva $^{3}$; Simone Vinhas de Oliveira ${ }^{3}$; Yeza Bozo Tonin ${ }^{3}$; Carlos Francisco Borges \\ Ferreira Pires ${ }^{3}$; Fernanda Dias Franco ${ }^{3}$; Bruna Deserti $^{3}$
}

\section{Resumo}

O uso dos recursos da informática no cotidiano dos lares e das empresas e a utilização da Internet como um dos principais meios de comunicação determinou a formação de uma nova sociedade, na qual o poder da informação passou a desempenhar um papel fundamental para qualquer indivíduo, e afetou a vida de milhões de pessoas. O Direito, como disciplina jurídica das relações humanas, não pode esquivar-se de tais conseqüências, sendo, portanto, submetido a diversos questionamentos. Nosso objetivo aqui é apresentar uma evolução histórica da Grande Rede, desde o nascimento do primeiro computador, até a significância do mundo virtual em nossos dias, caracterizando-se o que chamamos hoje de "Sociedade da Informação". Após o panorama da relevância da Internet e das Tecnologias da Informação na atual sociedade, apresentaremos alguns exemplos de como a informação influi nas relações sociais e de direito, tanto por meio da ofensa a direitos fundamentais, bem como à sua especial função na expansão empresarial. Dessa maneira, será demonstrada a extrema importância da Ciência Jurídica ao traçar parâmetros e conceitos nas relações atinentes a esse meio.

Palavras-Chave: Internet. Sociedade da Informação. Direito Eletrônico. Informática Jurídica. Economia Globalizada.

\begin{abstract}
With the arrival of information technology to the day to day life in many places of the world and the use of the Internet as the main type of communication, a new society has been organized, where information power has performed an important role in the life of almost everyone, having an effect on many people's lives. Law, as a juridical subject, can not avoid such consequences and should be taken into consideration. Our purpose is to present a historical evolution of the Web, since the first PC until the point that it reaches its importance in the world wide web nowadays, being denominated "Information Society". Having delineated an overview of the importance of the Internet and Information technologies in the current society, some examples will be shown on how information influences the social and law relations, through offense to fundamental laws as well as its special role in the business improvement. It will be demonstrated the great importance of the Juridical Science outlining concepts and parameters in this type of media.
\end{abstract}

Key-Words: Internet. Information Society. Electronic Law. Cybernet Law. Global Economy.

\footnotetext{
1 Doutora em Direito das Relações Sociais pela PUC-SP. Mestre em Direito das Relações Sociais pela UEL. Professora AdjuntoB de Direito Civil na Graduação em Direito e Mestrado em Direito Negocial da UEL.

2 Discente da Universidade Estadual de Londrina e bolsista da CNPq.

3 Discente da Universidade Estadual de Londrina.

${ }^{4}$ Inventor americano e fundador da empresa que deu origem à IBM - Internacional Business Machine
} 


\section{Introdução}

O surgimento da Internet foi, sem dúvida alguma, a matéria mais veiculada em todos os meios de comunicação, universitário e científico, na última década. No atual cenário de desenvolvimento do processo de globalização da economia, consolida-se uma nova forma de relação entre a sociedade, o Estado, as ONGs, a academia e especialmente os agentes econômicos. Num golpe de demolição à soberania dos países, por meio de um processo de internacionalização dos capitais e virtualização das relações econômicas, "a própria Sociedade se (re)organiza em Rede” (CASTEL apud SILVA JÚNIOR, 2001, p. 2)

O surgimento e a ampliação da Internet foi, sem dúvida alguma, a representação mais que empírica do fenômeno designado por "globalização", já que tal meio de comunicação passou a desempenhar um papel fundamental na sociedade mundial, pois vem mostrando que pode impedir qualquer tipo de barreira à essa extraordinária amplitude e profundidade das interações transnacionais.

Tal processo, no entanto, pode ser observado em qualquer ponto da esfera global, contudo devendose observar que, conforme os dizeres de Boaventura de Sousa Santos (2002, p.29), “estas transformações têm vindo a atravessar todo o sistema mundial, ainda que com intensidade desigual consoante a posição dos países no sistema mundial.”

A Nova Economia, como vem sendo chamada a forma de fazer negócios com o uso maciço de tecnologia, chegou a ser confundida com uma nova ordem econômica, pois nela não se aplicam mais as leis clássicas da economia. Por esse motivo, os negócios gerenciados sob tal ótica não vem dando os resultados esperados e as conseqüências, por não se observar velhas leis, estão começando a surgir, exigindo novos padrões de competitividade.

O crescimento do volume da complexidade das informações necessárias ao processo produtivo levou a aceleração da informatização das empresas. Em função disso, era de se esperar impactos econômicos positivos a partir do uso das redes de informação de alta tecnologia. No entanto, do outro lado da balança, sopesaram dúvidas acerca da eficácia e da segurança desse meio, e isso exigiu dos juristas a penetração dessa nova realidade cibernética nos domínios do Direito. A esse respeito, cabe considerar a imensa dificuldade no que se refere à proteção de direitos fundamentais, como a privacidade.

Objetiva-se apresentar linhas para o desenvolvimento de uma dogmática jurídica voltada para as soluções das questões advindas da utilização da Internet na denominada "Nova Economia”, onda a informação é tida hoje como um dos bens mais valiosos. Para isso, nada melhor do que, primeiramente, conhecer a trajetória do objeto material do qual partem todas as informações virtuais - o Computador.

\section{A História do Computador e da Internet - a Evolução Tecnológica}

\section{As Primeiras Máquinas de Calcular}

O termo computador é definido como aquele que faz cômputos, que calcula. Entretanto, as operações a serem realizadas por um computador vão além de simples contas aritméticas que marcaram o seu início e que motivaram sua construção.

O primeiro artefato humano utilizado para realizar contas foi o ábaco, de origem fenícia, que consistia num aparelho muito simples, formado por uma placa de argila onde se escreviam algarismos que auxiliavam nos cálculos.

O próximo passo na história dos computadores (1642) ocorreu quando o francês Blaise Pascal inventou a primeira máquina de calcular, a Pascalina, que funcionava por meio de engrenagens mecânicas e conseguia realizar somente a soma. Mas, já por volta de 1671, na Alemanha, Gottfried Leibnitz aprimora o invento de Pascal, de forma que esta nova máquina já era capaz de efetuar cálculos de multiplicação e divisão, tornando-se a antecessora direta das calculadoras manuais. 
No início do século XIX, o matemático inglês Charles Babbage percebe uma "harmonia natural entre máquinas e matemática”. De acordo com Babbage, as operações matemáticas repetitivas poderiam ser desenvolvidas com mais agilidade e confiabilidade pelas máquinas do que pelos homens. Assim, idealizou uma máquina a vapor, que seria capaz de realizar cálculos matemáticos mais complexos do que as quatro operações aritméticas básicas. Esta máquina, maior do que uma locomotiva, nunca foi construída na prática, mas as idéias do seu idealizador foram fundamentais para os progressivos avanços na computação mecânica, fazendo com que Charles Babbage fosse considerado o "Pai do Computador”.

\section{O Início da Era da Computação}

No ano de 1890, época do censo dos Estados Unidos da América, Hermann Hollerith ${ }^{4}$ percebeu que só conseguiria terminar de apurar os dados do censo quando já seria o tempo de se realizar outro. Então, inventou uma máquina à qual permitiu a apuração do resultado do censo em apenas seis semanas. Tal invento tinha como fundamento cartões perfurados para armazenar dados que seriam, naquela época, algo parecido com os disquetes.

Todavia, as engrenagens destes computadores mecânicos eram muito numerosas e complexas. Assim, em 1903, surge um computador 100\% eletrônico, e que utilizava a álgebra booleana, à qual consistia na famosa álgebra binária, do verdadeiro ou falso, do 0 ou 1 , base de todos os sistemas computacionais de hoje em dia.

Foi a partir da II Guerra Mundial que o desenvolvimento dos computadores eletrônicos ganhou mais força, pois o interesse pelas máquinas aumentou em vários Estados, visto o grande potencial estratégico que elas possibilitavam. Além disso, buscava-se uma forma de compartilhamento de informações de forma rápida e segura e máquinas capazes de executar cálculos balísticos com rapidez e precisão para serem utilizadas na indústria bélica.
Assim, os alemães desenvolveram o Z3, um computador capaz de projetar aviões e mísseis. Pode-se encontrar, a partir de então, cinco gerações de computadores daí originadas.

\section{Gerações de Computadores}

A primeira geração (1940/1952) é constituída por todos os computadores construídos à base de válvulas eletrônicas, cuja aplicação fundamental se deu nos campos científico e militar. As válvulas eletrônicas falhavam com freqüência, não funcionando grande parte do tempo e inspirando desconfiança. Durante esta fase, surgiu o ENIAC - Eletronic Numerical Interpreter and Calculator - computador criado por cientistas norte-americanos para fins militares.

Nació como consecuencia de un proyecto secreto del Departamento de Defensa, también en tiempos de la II Guerra Mundial, denominado Proyecto X (como en las películas). Desarrolado por John P. Eckert y John W. Mauchly, entró en funcionamiento en la Moore School de Filadelfia, la Escuela de Ingeniería Eléctrica de la Universidad de Penilvania. El 15 de Febrero de 1946 se hizo pública su existencia (NOTAS sobre Internet, 2004).

Nos computadores de segunda geração (1953/ 1963) as válvulas eletrônicas foram substituídas por transistores e os fios de ligação por circuitos impressos. Isso tornou os computadores mais rápidos, menores e de custo mais baixo.

Já a terceira geração de computadores (1964/ 1971) foi construída com circuitos integrados, proporcionando maior compactação, redução dos custos e velocidade de processamento da ordem de microssegundos. Tem início a utilização de avançados sistemas operacionais.

A quarta geração, de 1970 até hoje, é caracterizada por um aperfeiçoamento da tecnologia já existente, proporcionando uma otimização da máquina para os problemas do usuário, maior grau de miniaturização, confiabilidade e velocidade maior. 
A quinta geração de computadores pode ser retratada pelo surgimento da Internet, resultado da Guerra Fria. A injeção dada para o seu nascimento foi o lançamento do primeiro satélite espacial, o Sputnik, pela União Soviética. Quatro meses mais tarde, os Estados Unidos da América anunciavam a criação da ARPA (Advanced Research Projects Agency) com a missão de pesquisar e desenvolver altas tecnologias para as Forças Armadas, criandose então em 1969 a ARPANET (futura Internet). No início, a experiência foi entre dois computadores de pontos remotos dos Estados Unidos, que se comunicavam de uma forma mal sucedida, mas em 1973 já haviam 23 grandes computadores interligados.

Com o passar do tempo, o uso da ARPANET se expandiu para conectar também universidades e laboratórios, inicialmente nos Estados Unidos e posteriormente em outros países. Foi nessa época que o termo Internet começou a ser utilizado. Durante as duas décadas seguintes, a Internet ficou restrita aos meios acadêmico e científico, tendo seu uso comercial liberado nos Estados Unidos somente em 1987. Desde então a rede foi evoluindo até se tornar uma verdadeira teia de conexões.

Atualmente, passados pouco mais do que trinta anos desde a implementação da primeira rede (a ARPANET), a Internet já faz parte da vida de muita gente. Isto aconteceu em razão do advento dos navegadores (Netscape e o Internet Explorer, por exemplo) e da rede mundial de computadores (Word Wide Web).

\section{A informática jurídica e o direito cibernético}

A informática jurídica: aplicação e classificação

O juiz de direito de Pernambuco, Alexandre Freire Pimentel (2000, p.22), profetizou um futuro no qual os computadores passarão a processar todas as rotinas processuais: "participo de um projeto, em Pernambuco, de desenvolvimento de rotinas processuais informatizadas. Ainda estamos na petição inicial, mas o computador já consegue interpretá-la em sua íntegra”.

Ele reconhece que a interpretação de peças processuais por um computador esbarra em um problema - as ambigüidades e as contradições presentes na lei. Mas garante que essas questões serão superadas com o desenvolvimento de um novo ramo da Ciência Jurídica, cunhado por ele de "Direito Cibernético". De acordo com o magistrado, tal modalidade do Direito se dedicaria às aplicações futuras da informática aos fenômenos jurídicos.

Explica ainda que os princípios do Direito Natural, regendo a percepção que a sociedade tem sobre o que é justo ou não, já estão solidamente positivados nos ordenamentos jurídicos atuais. Nesse sentido, o conceito de norma jurídica e a instrumentalidade do processo deveriam ser repensados, de modo a flexibilizar a interpretação de certas regras.

"Temos sempre a mania de colocar o vinho novo em oldres velhos”, disse ele, referindo-se à resistência do Direito aos avanços tecnológicos. Pimentel alerta que não se deve confundir informatização com “computadorização”, e explica: “Não vamos resolver nossos problemas apenas colocando em mídia eletrônica o que hoje está em papel”. Para ele, a informática deve impulsionar uma nova concepção de processo, a qual, "além de incorporar as novas tecnologias, abranja o redimensionamento de conceitos jurídicos” (PIMENTEL, 2000, p. 23).

Uma vez que o objeto do interesse do mundo normativo não pode ser indiferente à evolução resultante do dinamismo das novas tecnologias, é natural que aumente a inquietação do homem por ser desprovido de instrumentos legislativos reguladores da revolução tecnológica.

Na verdade, são múltiplos e complexos os problemas jurídicos suscitados pela informática, inscrevendo-se, aliás, no quadro sistemático da generalidade dos tradicionais ramos do Direito. Numa época em que o computador é um instrumento fundamental no controle econômico ou fiscal, no 
planejamento sanitário, urbanístico, rodoviário, escolar ou militar, na comunicação social ou na pesquisa, não faria sentido que a informática deixasse de produzir o seu poderoso impacto no mundo do direito. Com efeito, a informática penetrou no universo jurídico e atingiu todas as realidades do mundo da Justiça.

Pode-se dizer que a informática jurídica é o ramo da informática que compreende as suas aplicações específicas ao mundo do Direito. Perez Luño a define como "uma disciplina bifronte, na qual se entrecruzam uma metodologia tecnológica com seu objeto jurídico, que por sua vez, condiciona as próprias possibilidades ou modalidades da aplicação dos recursos tecnológicos ao direito.” (apud PIMENTEL, 2000, p. 65) A classificação da informática jurídica varia conforme os pontos de vista pessoais dos juristas, assim destacando:

a) a informática jurídica de gestão ou operacional;

Dedica-se ao estudo da mecânica, do funcionamento das repartições, escritórios, e gabinetes jurídicos, tendo por finalidade a aplicação de princípios informáticos a toda e qualquer atividade jurídica de trabalho físico-material.

Este ramo da informática jurídica, com o seu aperfeiçoamento, recebeu a denominação de ofimática e burótica que, sob tais rótulos, visa a realizar, através de suportes informáticos ou telemáticos, operações destinadas a receber e transmitir qualquer informação. Permite o gerenciamento da justiça e também dos escritórios de advocacia - uma automação de todas as operações rotineiras e regulares, na forma de redação, contabilidade, comunicação e certificação -, visando à uniformização dos despachos e decisões judiciais.

b) informática jurídica de registros ou informática jurídica documental;

Esse âmbito da informática ocupa-se com todos os tipos de registros, objetivando facilitar aos usuários o acesso a todos os registros oficiais, com rapidez e facilidade. c) informática jurídica de decisão ou metadocumental;

Essa subespécie procura estabelecer determinadas pautas em hipóteses cujo trabalho intelectual é substituído por um labor repetitivo e rotineiro. Facilita-se, assim, a redação de modelos de decisões, para o bem do magistrado e do funcionamento judicial.

d) informática jurídica de ajuda à decisão;

Baseia-se no princípio de que o computador deve facilitar a informação adequada ao jurista, facilitandolhe a tomar decisões.

\section{A telemática e a cibernética}

A telemática pode ser conceituada, sucintamente, como comunicação informatizada, ou seja, técnica que trata da comunicação de dados entre equipamentos informáticos distantes uns dos outros. É um ramo do conhecimento cibernético e não deve ser confundida com a informática, pois aquela cuida dos problemas referentes à circulação de informações, o monopólio deste serviço, bem como sua regulamentação legal.

A cibernética, na definição de Weiner (apud PIMENTEL, 2000, p. 65) é a ciência do controle e da comunicação, por meio da arte de tornar a ação eficaz, ou seja, a noção de direção está relacionada com o seu controle mantenedor no caminho correto para que possua a eficácia desejada. Tem como propósito o desenvolvimento de uma linguagem capacitada para resolver o problema do controle da comunicação.

A cibernética, tendo como elementos constitutivos a informática e a telemática, tem no seu desenvolvimento uma das principais tendências da III Revolução Científico-Tecnológica, pois é reflexo da era do capital financeiro. Assim, por meio dela, pode-se constituir novas percepções, tanto no aspecto quantitativo como qualitativo de informações, práticas sociais e relacionamentos intersubjetivos.

A informática, a telemática e a cibernética, apesar de aparentemente semelhantes, possuem definições 
distintas e estão interligadas. É por meio delas que se constroem novas concepções de informação, sociedade e de relacionamentos intersubjetivos. Dessa maneira, se o Direito está inteiramente ligado à evolução dos aspectos sociais e culturais da sociedade, deve também se ligar aos aspectos revolucionários da tecnologia.

\section{A Disciplina Jurídica da Internet - O Direito Cibernético ou Direito Eletrônico}

O Direito Eletrônico é uma disciplina já reconhecida em nações mais desenvolvidas, possuindo todas as características de um direito especializado e, ao mesmo tempo, interdisciplinário e universal. Especializado porque seu objeto recai sobre a tecnologia informática, englobando o tratamento da informação e da comunicação. Interdisciplinário porque, hodiernamente, é difícil imaginar um só ramo do Direito que prescinda do Direito Eletrônico. Universal porque o transporte das informações ultrapassa os limites das fronteiras de um determinado Estado, encontrando-se assim presente em todos os países que façam uso da tecnologia computacional.

O fato de o Direito Eletrônico constituir-se num direito interdisciplinar, não significa a sua tradução num amálgama de diversas e dispersas normas pertencentes a diferentes setores da ciência jurídica, pois ele é constituído por um conjunto unitário de regras especificamente dirigidas à regulação de um objeto bem delimitado, enfocado por uma metodologia própria.

Tal disciplina surgiu da necessidade de se adaptar a legislação já existente em razão da nova realidade posta pela sociedade virtual, na medida que os sistemas jurídicos dos Estados nacionais não se encontram preparados para absorver tais mudanças. Os fatos e negócios jurídicos, até pouco tempo, fundavam-se na concepção de documentos escritos e arquivados em papel, além de definir relações pessoais em que nada tem haver com tal realidade, trazendo dúvida e insegurança jurídica para o desenvolvimento das relações intersubjetivas no meio virtual. O Direito Eletrônico ou Cibernético nada faz mais do que, ante a lacuna legislativa, apresentar uma teoria e uma análise lógica e jurídica dos litígios dos litígios que nascem em função da Internet.

\section{Os Impactos da Internet na Economia Globalizada - A Sociedade da Informação}

O valor da tecnologia da informação e da Internet reside em sua capacidade de armazenar, analisar e transmitir informações instantaneamente para qualquer lugar, a um custo ínfimo, ampliando o poder da mente. Estando a surgir um verdadeiro mercado eletrônico globalizado, nada mais importante do que o poder sobre a informação, sendo evidente a posição de destaque da Internet no novo espaço global. Ela atrai e consome o interesse principal sobre Tecnologias da Informação (TI), concentrando atenções e investimentos, seja no âmbito doméstico ou corporativo. É ao redor de uma das mais importantes inovações na história da tecnologia que as principais TIs têm se desenvolvido.

O aproveitamento das inovações deve preceder uma adaptação do sistema produtivo. A tecnologia da informação resulta da sinergia entre infra-estrutura de telecomunicações, desenvolvimento de software, padrões e habilidade humana. Então, é de se esperar um amadurecimento de tais fatores antes do surgimento de bons resultados. Apenas o desenvolvimento de softwares não representa um grande avanço para a maioria dos paises que vem buscando difundir o acesso a Internet.

Apesar de os agentes econômicos terem iniciado o movimento de adaptação de novas tecnologias a partir da década de 70 , não se pode deixar de considerar como extremamente importantes os avanços tecnológicos que sofisticaram e, principalmente, baratearam o uso dos meios de informação. Observase que a redução no preço dos computadores tem levado a uma difusão do seu uso, aumentando também a sua eficiência em diversas áreas como ciências, manufatura, marketing e finanças. Pequenos 
computadores pessoais fazem tarefas típicas de grande mainframes. Equipamentos exclusivos de caríssimos experimentos científicos tornaram-se tão baratos que passaram a fazer parte de bens de consumo duráveis para todas as classes sociais.

Através de alguns valores se vê que a crença no potencial da Tecnologia de Informação é bastante representativa. Atualmente, o mundo é mais rico do que era nos primeiros dias da economia mundial. A era digital deu às pessoas mais acesso a mais informações do que elas possivelmente poderiam digerir. Com isso, aumentou a demanda por ferramentas para ajudar as pessoas a assimilar as informações mais depressa e tomar decisões mais rápidas. Os consumidores têm acesso muito rápido às informações e, também por esse motivo, as empresas precisam ter acesso muito rápido à elas, além de encontrar maneiras de progredir e competir na nascente economia digital, que a cada dia se torna mais complexa e difícil de ser compreendida e desenvolvendo profundas questões de ordem jurídica.

Nesse sentido, o Direito, como ciência social que estuda e normatiza os fatos reclamados pela sociedade, propõe-se, através de uma nova disciplina jurídica, o Direito Eletrônico, a investigar essa denominada "Sociedade da Informação" inserida no contexto da globalização mundial, e estabelecer normas para o melhor uso da Internet, bem como para o desenvolvimento de novas tecnologias da informação. Veja, a seguir, como o Direito e Internet estão completamente associados.

\section{A Internet e os Direitos da Personalidade}

$\mathrm{O}$ direito à intimidade, à vida privada, à honra, à imagem, ou seja, os direitos da personalidade, elencados no art. 5. ${ }^{\circ}, \mathrm{X}$, da Constituição Federal, possuem características próprias que os diferem dos demais. São eles inalienáveis, invioláveis, não os podem retirar de alguém, já que são inerentes à própria pessoa humana.

A privacidade, num sentido genérico, significa o conjunto de informações acerca do indivíduo que este pode decidir manter sob seu exclusivo controle, ou comunicar, decidindo a quem, quando, onde e em que condições, sem a isso ser legalmente sujeito. Tal esfera, assim, é ampla e se refere não só às relações familiares, como também o nome, os hábitos, a imagem, os segredos.

$\mathrm{O}$ direito à intimidade seria, portanto, um aspecto daquela esfera maior, a da privacidade, constituindo a esfera íntima da pessoa, segredos e particularidades de foro íntimo do indivíduo. É o modo de ser da pessoa; aquilo que é secreto aos demais, que é pertinente somente ao seu detentor. Abrange, assim, a inviolabilidade de domicílio, o sigilo da correspondência, o segredo profissional.

Talvez o sigilo da correspondência, garantia de liberdade de expressão do pensamento, em que se encontra a proteção dos segredos pessoais que dizem respeito unicamente aos correspondentes, seja o aspecto mais importante ao tema aqui a ser tratado.

A vida privada, segundo José Afonso da Silva (2000, p. 212) para ser conceituada deve-se partir do pressuposto de que a vida compreende dois aspectos: um, voltado ao exterior, e outro, para o interior. Esta primeira faceta engloba as pessoas e as suas relações sociais, atividades públicas, e pode ser objeto de divulgação, já que é pública. O segundo aspecto da vida é aquele que se volta para o seu interior, sobre a pessoa e os membros de sua família, seus amigos, ou seja, a vida privada do indivíduo, inviolável segundo a Constituição Federal.

Também são invioláveis a honra e a imagem das pessoas. A honra é o "conjunto de qualidades que caracterizam a dignidade da pessoa, o respeito dos concidadãos, o bom nome, a reputação” (SILVA, 2000, p. 212). Vê-se, portanto, que é fundamental o direito da pessoa proteger tais atributos. Já a imagem se liga ao aspecto físico e se reflete também na personalidade moral do indivíduo.

A violação a esses direitos, em algumas hipóteses, constitui ilícito penal, além do que a própria Constituição explicita o direito à indenização pelo dano moral dela decorrente. 
Na relação entre os direitos da personalidade e a Internet deve-se analisar o tema sob três principais aspectos: a inviolabilidade das informações contidas nos e-mails, o sigilo de dados e informações pessoais e, por último, a propagação de imagens via Internet.

\section{A inviolabilidade das informações contidas nos e-mails}

A questão que aqui surge é se a confidencialidade dos e-mails se compararia ao sigilo da correspondência, protegido pela Constituição Federal em seu art. 5. ${ }^{\circ}$, XII.

O e-mail constitui hoje uma das formas mais comuns de liberdade de expressão e de pensamento, devendo, portanto, ser resguardado afim de que se proteja a intimidade do remetente e a do destinatário.

Não se poderia, dessa forma, permitir a inspeção sobre o conteúdo das mensagens enviadas, já que o dispositivo constitucional não faz distinção entre o correio postal e o eletrônico e mesmo porque, a Internet representa apenas uma evolução na forma com que as correspondências são transmitidas. Por essa razão, seria perfeitamente possível a aplicação das regras pertinentes a outros meios de comunicação como, por exemplo, o art. 151 do Código Penal brasileiro. A inviolabilidade das informações transmitidas é a mesma, pouco importando o meio pelo qual sua transmissão se dá.

Questão interessante, também, neste aspecto, é o da possibilidade ou não de monitoramento pelo empregador dos e-mails enviados e recebidos por seus empregados. Haveria, neste caso, violação ao direito à intimidade e à privacidade? O empregador não poderia filtrar os e-mails enviados por máquinas de sua propriedade, nem mesmo para evitar que crimes sejam cometidos em seu estabelecimento? Estas são questões ainda não pacificadas pela doutrina, pela jurisprudência, ou mesmo pela legislação, que é escassa.

\section{Sigilo de dados e informações pessoais}

A questão da confidencialidade de dados e sigilo de informações é preocupante na medida em que cada vez mais os serviços anunciados pela Internet são contratados.

Para que se possa ter acesso a tais comodidades, é necessário o preenchimento eletrônico de cadastros, onde são lançados informações e dados pessoais, patrimoniais, remuneratórios, entre outros, não havendo garantias ao seu sigilo.

Verdadeiros bancos de dados se formam sem que haja preocupação com a forma com que tais informações serão utilizadas (por quem, para quem), desrespeitando-se, muitas vezes, a individualidade dos usuários, a qual fica inteiramente fragilizada.

Há evidente necessidade de legislação, no tocante a estes aspectos, que preveja o sigilo de tais informações e a própria responsabilidade civil do ofertante, em caso de inobservância deste preceito, mesmo porque, a inviolabilidade do sigilo de dados somente pode ser quebrada mediante ordem judicial, como a própria Constituição Federal em seu art. 5. , $\mathrm{X}$, estabelece.

\section{Propagação de imagens de caráter pessoal ou desabonadoras da moral}

Em razão da capacidade de veicular informações, bem como a velocidade com que estas são propagadas, o dano moral no âmbito da Internet toma proporções maiores e mais danosas que aquele veiculado por outros meios de comunicação.

O problema não reside apenas em não se evitar a inserção e a propagação de fotos desabonadoras da moral, ou mesmo ofensas como a injúria, calúnia e difamação na Internet, o que seria impossível, mas também na eficácia da repreensão à conduta danosa.

Como já visto anteriormente, a Internet se sujeita aos comandos da Constituição Federal, que em seu art. $5 .^{\circ}, \mathrm{V}$, protege a honra e a imagem das pessoas ao prever a possibilidade de indenização por dano 
moral. Mas para que esta norma se torne eficaz é preciso a identificação dos transgressores e está só ocorre se os agentes públicos realmente forem equipados, não só com máquina, mas também com leis. A segurança jurídica só ocorrerá na medida em que a transgressão ao bem jurídico protegido, no caso a honra, seja efetivamente punida. Daí a necessidade de legislação específica, com o intuito de coibir tais práticas, resguardando-se os direitos do ofendido.

\section{Empreendedorismo e Internet}

O estabelecimento de uma harmonia entre o empreendedorismo e o uso da Internet é a grande questão de nossos tempos. Ora, como expandir a atividade sem correr riscos desnecessários? Tal pergunta tornou-se inevitável frente aos avanços ocorridos nas últimas décadas, principalmente não que tange ao crescimento de empresas ligadas intimamente com a Internet.

O que ocorre, em verdade, é que a inclusão dos produtos de determinada empresa no mundo global caracteriza-se tanto por ser um sonho de quem busca a expansão de sua atividade no mercado quanto em problemas relacionados com a compra, a venda, e a distribuição, isso sem falar na existência e na validade dos contratos celebrados via Internet.

O termo empreendedorismo é a livre tradução que se faz da palavra entrepreneurship. Designa uma área de grande abrangência e trata de outros temas, além da criação de empresas de geração do auto-emprego (trabalhador autônomo); de empreendedorismo comunitário; infraempreendedorismo (o empregado empreendedor); políticas públicas (políticas governamentais para o setor).

Sendo assim, se a pessoa desejar abrir uma empresa, realizar um sonho, ganhar autonomia e independência financeira, é preciso que tenha informações seguras e confiáveis para ser bem sucedido. Geralmente, o empreendedor escolhe um negócio que já conhece e no qual tem alguma experiência profissional ou técnica. O melhor negócio, porém, é aquele que consegue juntar experiência profissional e os conhecimentos pessoais com as necessidades do mercado. Para uma maior segurança, deve o empreendedor utilizar-se de informações. A informação reduz a incerteza e melhora o desempenho. Para obtenção de sucesso nessa investida, o comerciante deve estar sempre atualizado, oferecendo praticidade e qualidade naquilo que apresenta a quem está do outro lado da tela.

Nesse sentido, a Internet representa uma nova área de atuento e aprendendo com os erros e acertos ao longo do caminho. Isso diminui a diferença de competitividade entre aquele que já está no mercado e quem está entrando nele agora. Também relacionado à questão da novidade da área é fato de que ainda existem muitas fatias de mercado interessantes a serem exploradas. Pequenos segmentos eventualmente não interessam às grandes empresas, ou passaram despercebidos, ou que ainda não estão totalmente maduros, podem representar uma excelente oportunidade de negócios para um empreendedor com visão e mentes abertas. Observado isso, há que se fazer a distinção entre dois tipos de comércio eletrônico mais freqüentemente utilizados: um é o B2C (Business to Consumer), o negócio entre um comerciante e o consumidor final e o outro é o B2B (Business to Business), ou comércio entre empresas (BLUM, 2001, p. 223-229 passim), que se utiliza da Internet como via que proporciona um aumento de produtividade maior rotatividade de negócios.

Além disso, há que se falar na principal vantagem de negócios praticados na rede, qual seja, o custo de operacionalização. Sem dúvida, o desembolso é sensivelmente menor para um empreendimento na Internet, particularmente no caso do varejo. No que se refere a investimentos e custos, o fato concreto é que um negócio na Internet leva uma enorme vantagem. Para um empreendedor que, via de regra, dispõe de poucos recursos, esse é um aspecto extremamente relevante, posto que o negócio pode ser implantado aos poucos e testado. Diferentemente de um negócio tradicional, na qual o início das 
operações geralmente ocorre somente com o empreendimento totalmente estruturado, um negócio na Internet pode ser implantado em etapas, diluindo o investimento e facilitando a correção de erros.

\section{Conclusão}

Diante da nova sociedade que se constrói, baseada no poder da informação, a Internet se tornou uma locomotiva da economia mundial. O manifesto da Nova Economia, por meio de um movimento de proporções comparáveis à Revolução Industrial, trouxe, com a chegada da Internet nos processos de negócios empresariais, a explosão de produtividade e a transformação da economia global, representada por empresas amadurecidas.

A ordem hoje para o sucesso empresarial é a informação farta e bem administrada, fluindo, de maneira a garantir um processo mais curto, barato e com garantia de qualidade total. Não se deve esquecer, porém, que, antes de tudo, tais informações sejam obtidas por meios lícitos e não violem direitos fundamentais, como os direitos da personalidade.

O Direito, por sua vez, vem recepcionando as relações no mundo virtual da melhor maneira possível, utilizando-se da informática, da telemática e da cibernética para construção de uma nova disciplina jurídica, o Direito Eletrônico. Com ele, garantir-se-á a segurança e o tratamento da informação como bem jurídico de alto valor.

Hoje, a informação digital muda o curso de estratégia, e é por isso que ignorar ou dar pouca atenção à tecnologia pode significar até o fim de uma empresa. Ou se desperta para o novo mundo ou não se sobrevive à intensa competição instalada no mercado globalizado.
É nesse contexto que o Direito apresenta-se ao definir regras e oferecer garantias ao bom funcionamento desta nova ordem mundial, adequando-se às necessidades das partes e resolvendo os possíveis conflitos decorrentes de tal relação.

Interessante se faz observar a criação de normas comuns aos países, já que as relações estabelecidas entre as partes, em que as matérias jurídicas se colocam, ultrapassam as fronteiras de atuação de nossas leis, proporcionando à rede uma abrangência pelo mundo e envolvendo situações tão comuns como a de uma pessoa que vai ao supermercado fazer uma simples compra.

\section{Referências}

BLUM, Renato Opice (Coord.). Direito eletrônico: a internet e os Tribunais. Bauru: Edipro, 2001.

NOTAS sobre a internet. Disponível em: <http:// www.zator.com/Internet/N_2.htm> Acesso em: 20 abr. 2004.

PIMENTEL, Alexandre Freire. O Direito cibernético: um enfoque teórico e lógico aplicativo. Rio de Janeiro: Renovar, 2000.

SANTOS, Boaventura de Souza Santos (Org.). A globalização e as Ciências Sociais. 2. ed. São Paulo: Cortez, 2002.

SILVA, José Afonso da. Curso de direito constitucional positivo. 17. ed. São Paulo: Malheiros, 2000.

SILVA JÚNIOR, Roberto Roland Rodrigues. Internet e direito: reflexões doutrinárias. Rio de Janeiro: Lúmen Júris, 2001. 